\title{
$5 \mathrm{~kW}$ Multilevel DC-DC Converter for Hybrid Electric and Fuel Cell Automotive Applications
}

\author{
Faisal H. Khan ${ }^{1,2}$ \\ fkhan3@utk.edu \\ ${ }^{1}$ Electric Power Research Institute (EPRI) \\ 942 Corridor Park Blvd. \\ Knoxville, TN 37932
}

\author{
Leon M. Tolbert ${ }^{2}$ \\ tolbert@utk.edu \\ ${ }^{2}$ The University of Tennessee \\ Electrical and Computer Engineering \\ Knoxville, TN 37996-2100
}

\begin{abstract}
A $5 \mathrm{~kW}$ multilevel modular capacitor clamped dc-dc converter (MMCCC) for future hybrid electric vehicle and fuel cell automotive applications will be presented in this paper. The modular structure of the MMCCC topology was utilized to build this $5 \mathrm{~kW}$ converter with high reliability and fault bypassing capability. Moreover, the circuit has flexible conversion ratio that leads to establish bi-directional power management for automotive applications. In addition, the MMCCC exhibits better component utilization compared to the well known flying capacitor dc-dc converter. Thus, the MMCCC circuit can be made more compact and reliable compared to many other capacitor clamped dc-de converters for high power applications.
\end{abstract}

\section{INTRODUCTION}

Recent developments in hybrid automobile industry have created a massive requirement for various power electronic converters. The present trend is to use more and more electronic appliances (essential and luxury components) in automobiles [1, 2]. An increasing demand exists for the $\mathrm{dc}$ appliances in future automobiles, and the standard $14 \mathrm{~V}$ bus will not be suitable to supply the power requirements for those dc loads.

A $42 \mathrm{~V} / 14 \mathrm{~V}$ bus system named as " $42 \mathrm{~V}$ PowerNet" was proposed [2] several years ago. In this system, there will be two voltage buses in the electrical system of a vehicle. Some electrical loads will be connected to the $42 \mathrm{~V}$ bus, and some of the existing electrical loads will remain connected to the $14 \mathrm{~V}$ bus. This system might have one or two sets of batteries; one for $14 \mathrm{~V}$ and one for $42 \mathrm{~V}$ bus. In both cases, there will be a bi-directional converter that can manage power flow between the two voltage buses. In this way, loads connected at the $42 \mathrm{~V}$ bus can be powered from the battery connected on the same bus or from the $14 \mathrm{~V}$ bus. This is also true for the loads connected at the $14 \mathrm{~V}$ bus.

The development of a compact, high efficiency dcdc converter can introduce several modifications to the overall automobile design. The overall performance of the bi-directional dc-dc converter will impact if the $42 \mathrm{~V} / 14 \mathrm{~V}$ dual bus system will be a successful and cost effective solution for future automobiles. Especially in automotive applications where high ambient temperature $\left(\sim 200^{\circ} \mathrm{C}\right)$ is present, conventional dc-dc converters with magnetic elements can be very inefficient, and dc-dc converters with bulky inductors can suffer from limited space issue.

The other criterion that needs to be fulfilled from this bi-directional converter is high efficiency even in partial loads. Classical dc-dc converters suffer from limited efficiency at partial loads, and the maximum efficiency is achieved at full load. Thereby, a new dc-dc converter having an operating principle other than the inductive energy transfer method could be advantageous. Several capacitor clamped converters can be considered as a solution to meet this criterion to achieve high efficiency operation and bi-directional power handling capability.

Bi-directional power management is an important attribute of a dc-dc converter used in several applications. In a hybrid automobile, there are many electrical loads grouped into two main categories depending on the voltages they use. Fig. 1 shows the typical arrangement of the power electronic modules in a fuel cell vehicle. The main traction motor is powered from the high voltage bus (around $500 \mathrm{~V}$ ). There are also low voltage loads that need to be powered from a low voltage source in the range of 40-50 V.

The low voltage source could be a battery or a stepped down voltage from the high voltage battery pack or any source. When the high voltage source is a fuel cell, the low voltage source is normally a battery pack. During the start up time of the vehicle, the low voltage battery pack delivers power to the fuel cell system and to the main motor, and the low voltage loads 


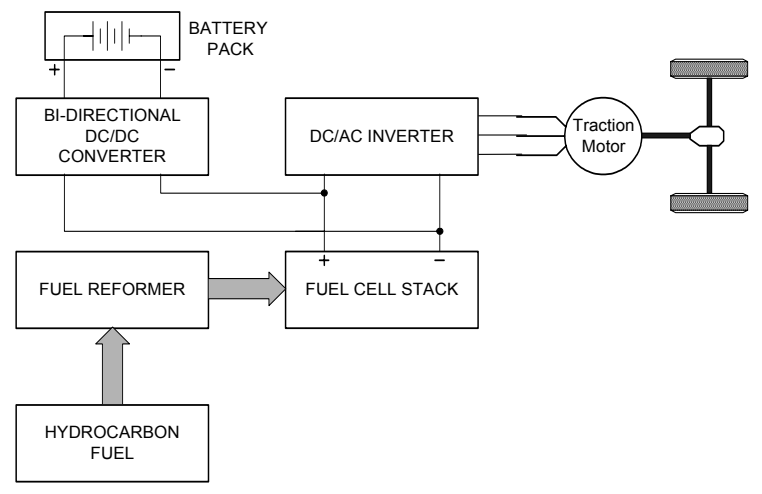

Fig. 1. Typical topological arrangement of a hybrid fuel cell vehicle drive train [3].

in the vehicle [3]; the dc-dc converter works in the up conversion mode.

Once the fuel cell is ready, it provides power to the main motor and low voltage loads. The low voltage battery is also charged from the fuel cell if required. During this time, the dc-dc converter works in the down conversion mode. Thus, a dc-dc converter used in the system must have the capability to deliver power in both directions depending on the state of the fuel cell or the battery voltage.

There are several existing topologies of capacitor clamped multilevel dc-dc converters [4-12]. Many of them have semi-modular structure, and some of them can be operated at very high efficiency. However, the converter presented in [13] was a new topology that combines the advantageous aspects of many capacitorclamped converters. The multilevel modular capacitor clamped dc-dc converter (MMCCC) presented in [13] has been modified to meet the load requirement in future hybrid and fuel cell vehicles.

The present paper will introduce a $5 \mathrm{~kW}$ MMCCC converter with several additional features. The 6-level MMCCC topology shown in Fig. 2 has a modular structure, and the $5 \mathrm{~kW}$ prototype can establish a bidirectional power management system for future hybrid electric and fuel cell vehicular drive train. This proof of concept converter described in this paper could be used to establish power management between a $250 \mathrm{~V}$ and $50 \mathrm{~V}$ dual bus system; which leads to build the circuit with a conversion ratio of 5 for normal operation.

\section{Bi-Directional Power Management}

One unique feature of the MMCCC topology is its modularity, and any of the active modules used in the circuit can be bypassed. When transistor $\mathrm{SB}_{1}$ in Fig. 3 is continuously on and the other two transistors are continuously off, the module works as a bypass module. In this situation, the module does not participate in the operation of the converter and simply bypasses the current through itself. During the normal operation that is defined as the active state, all three transistors in a module are controlled by the proper gate-driving signals. Thus, any module can be operated in either active state or bypass state by activating appropriate control signals in a module. In this way, it is possible to increase or decrease the number of levels and thereby the conversion ratio $(\mathrm{CR})$.

For a dual bus system, the bi-directional converter can transfer power from high voltage bus to the low voltage bus or vice-versa. The $\mathrm{CR}$ of the converter depends upon the number of active modules and the duty ratio of the gate driving signal. Two different gate drive signals are fed to each of the modules in the MMCCC converter, and this pair of signals is common to all modules. When the number of active modules is even such as 4 , these two signals have durations of $0.6 \mathrm{~T}$ and $0.4 \mathrm{~T}$, where $\mathrm{T}$ is the time period of the gate driving signals. The signal with duty ratio 0.6 is fed to the transistors with suffix $\mathrm{SR}_{\mathrm{X}}$ (such as $\mathrm{SR}_{1}, \mathrm{SR}_{2}$ etc.). On the other hand, $\mathrm{SB}_{\mathrm{X}}$ transistors are controlled by the signal that has a duty ratio of 0.4 . For an odd number of active modules, each of the signals has duration of $0.5 \mathrm{~T}$. Thus, when 4 modules are active, the $\mathrm{CR}$ is 5 ; and the CR is 6 for 5 active modules in the system.

For any number of active modules, if the duty ratios

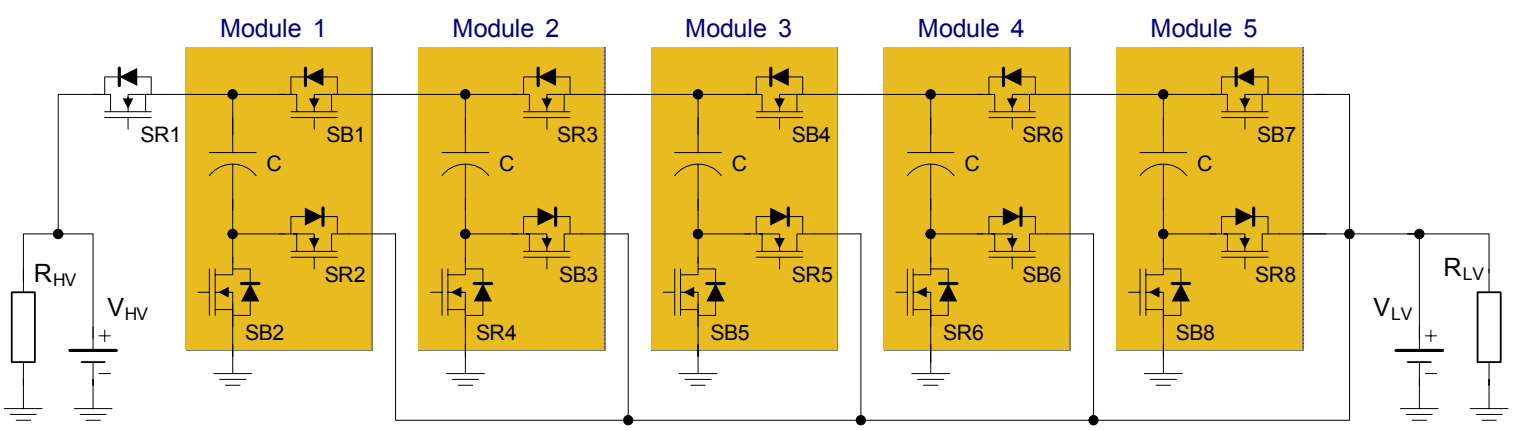

Fig. 2. The schematic of a 6-level MMCCC converter with flexible conversion ratio (CR). 


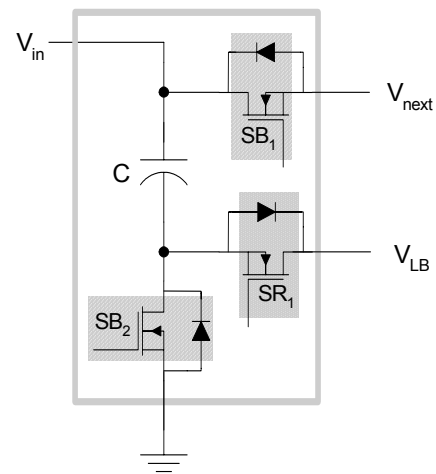

Fig. 3. Modular block of the MMCCC.

of the two gate driving signals are reduced, the CR increases from the previous value, and it is no longer an integer value. Thus, for 4 active modules, if the two signals' durations are reduced from their original value of $0.6 \mathrm{~T}$ and $0.4 \mathrm{~T}$, a non-integer $\mathrm{CR}$ of more than 5 is obtained. This is used to control the power flow in both directions. When a multilevel converter is used to transfer power between two voltage sources, the direction of power flow is governed by the ratio of the voltage sources (RVS) and the CR. Unlike the RVS, the $\mathrm{CR}$ is usually an integer value for capacitor clamped converters, and when the CR is greater than the RVS, the low voltage source transfers power to the high voltage (HV) side. On the other hand, a CR smaller than the RVS will force the converter to transfer power from the high voltage side to the low voltage (LV) side. However, depending on the source voltages, RVS may change; and for a fixed CR, the power flow may change its direction, even if it is not desired. In this situation, a variable $\mathrm{CR}$ is needed, and in the MMCCC circuit, the $\mathrm{CR}$ value can be changed by adding or subtracting a level in the system. Thus, a 6-level converter can be operated in either a 5 or 6 level configuration.

The bi-directional power management of the MMCCC converter can be explained by using a specific example as shown in Fig. 4. Fig. 4(a) shows an operation when the high voltage source is feeding power to the low voltage side. During this time, the CR was 6 ,
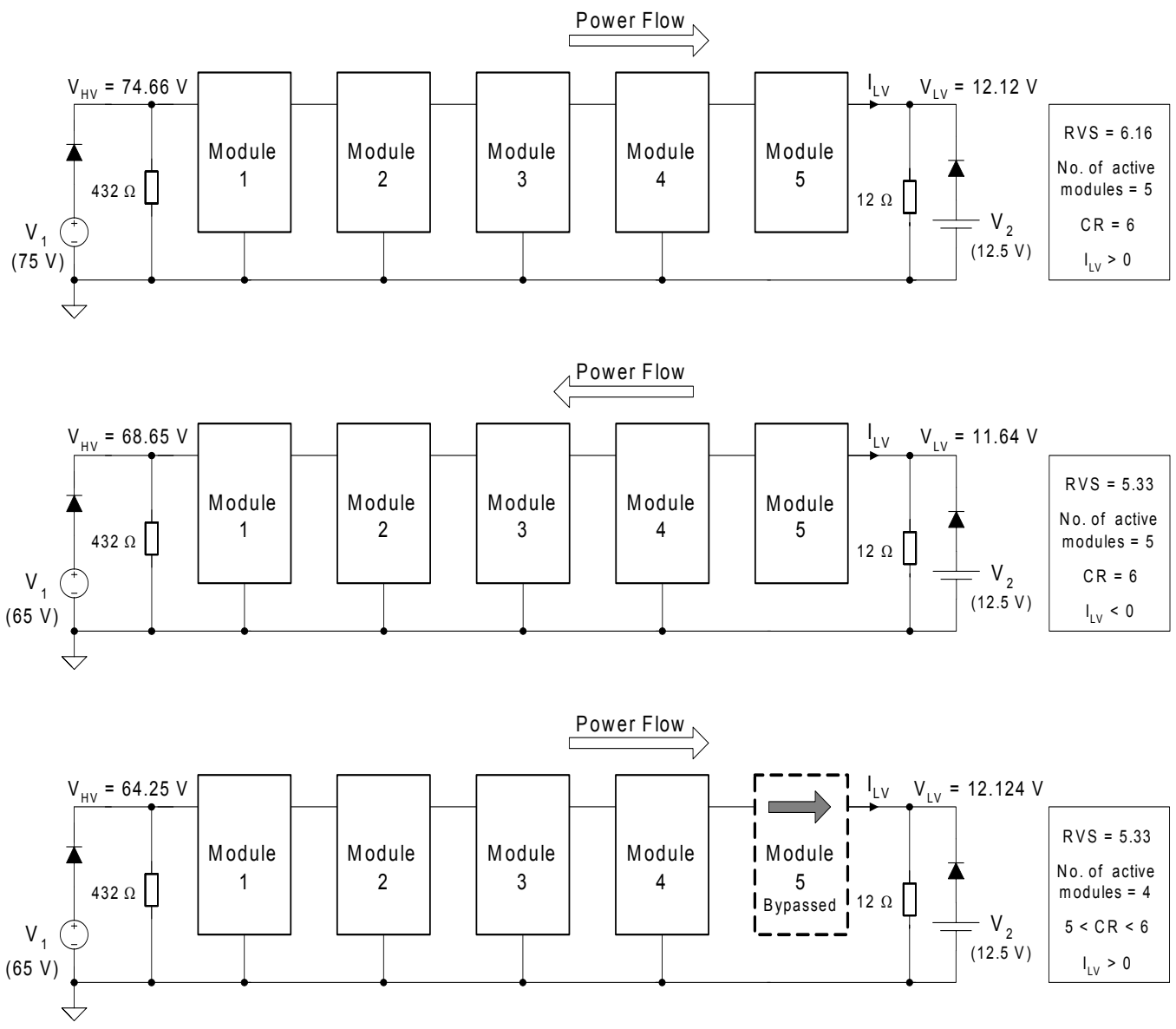

Fig. 4. The bi-directional power management operation, (a) $\mathrm{V}_{1}$ is feeding power to LV side using 5 active modules,

(b) $\mathrm{V}_{1}$ has decreased, power flow direction has been reversed, and $\mathrm{I}_{\mathrm{LV}}$ has become negative; $\mathrm{V}_{2}$ is feeding power to $\mathrm{HV}$ side, (c) module 1 has been bypassed and a conversion ratio less than 6 is achieved using 4 active modules. 
and the ratio of voltage sources (RVS) was 6.16. When $\mathrm{V}_{1}$ is reduced to $65 \mathrm{~V}$, RVS drops to 5.33 , and the direction of power flow is reversed. This is shown in Fig. 4(b).

To maintain the same current to the low voltage side, the CR of the circuit needs to be less than 5.33, and this is done by bypassing a level, and changing the duty ratio of the gate drive signals. This operation is shown in Fig. 4(c). If the gate-drive signal is not controlled, 4 active modules will produce a $\mathrm{CR}$ of 5 , and the LV side current will be very high. Thus, by reducing the duty ratio of the gate drive signals, a CR close to 5.33 is obtained, and the LV side current can be controlled.

\section{SiMULATION RESULTS}

To examine the bi-directional power management capability of the MMCCC, a 5-level circuit was simulated in PSIM. The high voltage side of the converter was connected to a $220 \mathrm{~V}$ battery, and the low voltage side to a $42 \mathrm{~V}$ battery. Fig. 5 shows the simulation results of the bi-directional power management operation of the converter. These results demonstrate the variable conversion ratio of the MMCCC topology, and shows how this attribute can be used to control the power in any direction regardless of the end node voltages. Fig. 5(a) shows the charging current to the LV side battery; it had an average value close to $17 \mathrm{~A}$. During this time, RVS was 5.238 and CR was 5. So, power was flowing from the HV side to the LV side.

To investigate the circuit's behavior when the RVS is changed, the HV side battery voltage was reduced from $220 \mathrm{~V}$ to $200 \mathrm{~V}$. In Fig. 5(b), the charging current to the LV side battery is shown. This current has a negative average value meaning that the LV side battery is actually charging the HV side battery. The LV side battery is now being discharged at a rate of approximately $17 \mathrm{~A}$.

Because the HV side voltage is reduced, the power flow direction has been reversed; however, it is required to keep the power flow direction as before. To implement that, CR must be smaller than RVS. Now the $\mathrm{CR}$ of the circuit is reduced from 5 to 4 by bypassing one level. However, the present RVS is 4.76 , and it is much higher than the CR (4). This condition causes a very high current flow from the HV side to the LV side. To avoid that, the duty ratio of the MMCCC's clock circuit is reduced to 0.03 for both $\mathrm{SR}_{\mathrm{x}}$ and $\mathrm{SB}_{\mathrm{x}}$, and thus a CR higher than 4 but less than 5 is obtained.

Fig. 5(c) shows the charging current to the LV side battery after reducing the CR from 5 to 4 by bypassing a level and reducing the duty ratio. In Fig. 5(c), the charging current still has an average of approximately $16.28 \mathrm{~A}$ which is very close to the original value $(17 \mathrm{~A})$. Because the new duty ratio is quite small, the charging

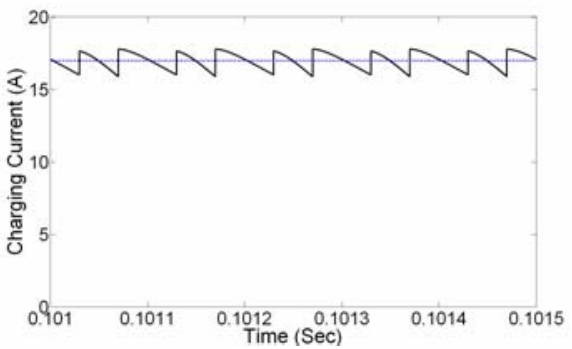

(a)

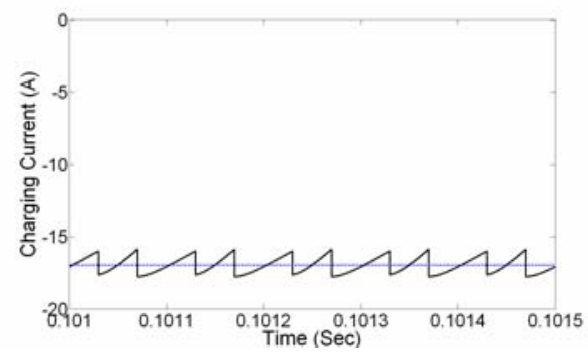

(b)

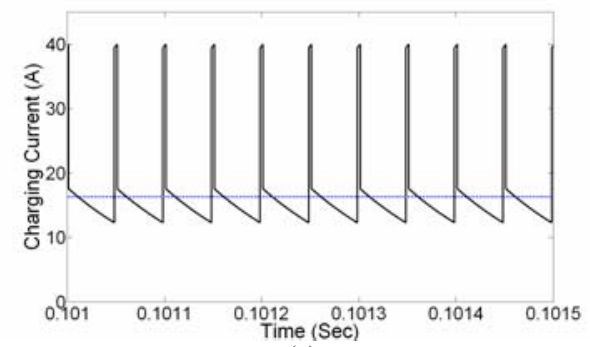

(c)

Fig. 5. The simulation results of the charging current of the MMCCC. (a) the charging current of the low voltage side battery when $\mathrm{V}_{\mathrm{HV}}$ is $220 \mathrm{~V}$, (b) the charging current when $\mathrm{V}_{\mathrm{HV}}$ is reduced to $200 \mathrm{~V}$ ( $\mathrm{I}_{\mathrm{CH}}$ becomes negative), (c) the charging current with three active modules; one module has been bypassed and reduced duty ratio ensures a conversion ratio less than 5 .

current has a high peak value that is close to $40 \mathrm{~A}$ for this setup. The flexible CR of the MMCCC is the key factor here that is responsible for the bi-directional power management.

\section{EXPERIMENTAL RESULTS}

Fig. 6 shows the prototype of a $5 \mathrm{~kW}$ MMCCC converter. This converter is designed to achieve any conversion ratio up to 7 . Thus, the converter has 6 modules, and each module has its own gate drive circuit on board. A control circuit using Parallax Stamp BS2P40 has been programmed to generate the proper gate signals for the various transistors in each module. Each module has 3 pairs of MOSFETs to be used as $\mathrm{SB}_{1}, \mathrm{SB}_{2}$, and $\mathrm{SR}_{1}$ in Fig. 3, and they were used in pair to enhance the current handling capability. For normal operation with a CR of 5, the last two modules from the right are used as bypass module. As explained earlier, to implement the bi-directional power management, one 


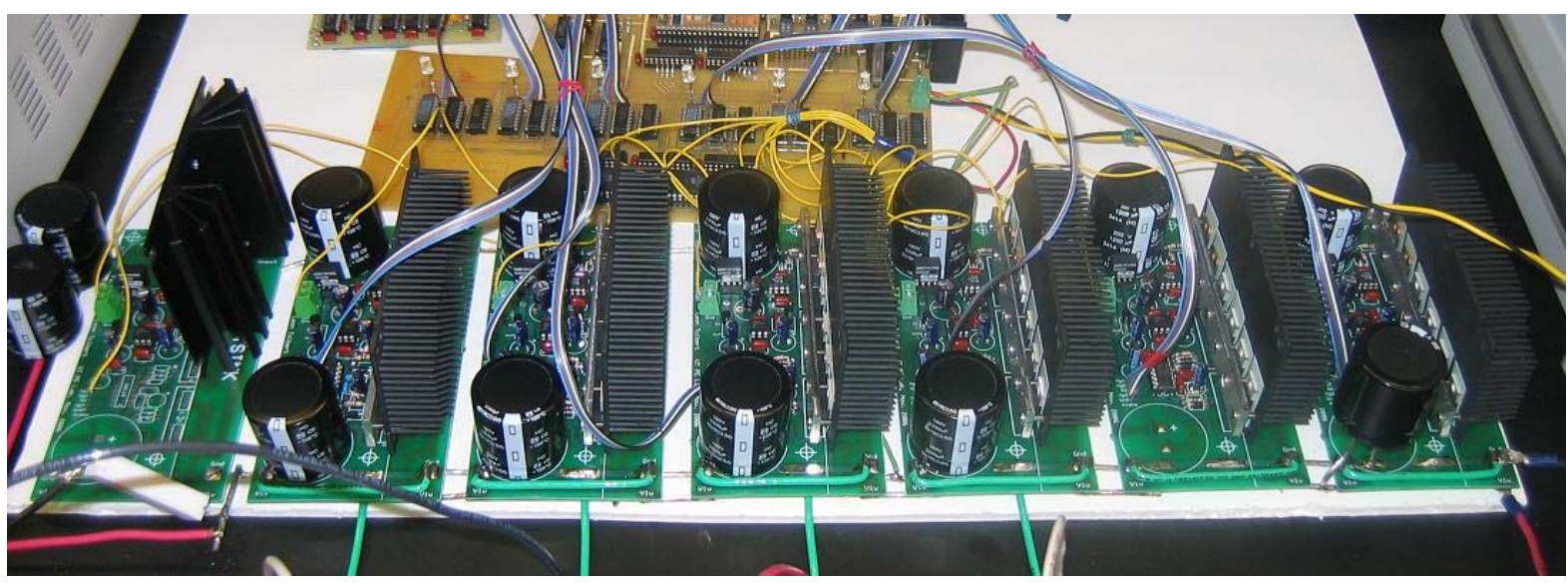

Fig. 6. The 6-level $5 \mathrm{~kW}$ version of the MMCCC with 6 modules. The sixth module (first one from right) is bypassed for normal operation.

additional module is required. In addition, to introduce some level redundancy and fault bypass capability in the system, one module is used as reserve. This is why the converter was fabricated with 6 modules.

\section{A. Bi-directional power management}

To test the bidirectional power management of the converter, the arrangement shown in Fig. 4 was followed, and the MMCCC circuit was connected between two dc power supplies at LV and HV side. Two sets of loads were also connected at HV and LV side. The HV side voltage was kept at $75 \mathrm{~V}$ and the LV side voltage was $12.5 \mathrm{~V}$. Initially the CR was 6 , and for this $\mathrm{CR}$, the HV side source was sending power to the LV side loads. The LV side load current generated by the $\mathrm{HV}$ side is shown in Fig. 7(a). In this figure, $\mathrm{V}_{\mathrm{HV}}$ is sending power to the LV side, and the average $\mathrm{I}_{\mathrm{LV}}$ was around $1 \mathrm{~A}$.

When $\mathrm{V}_{\mathrm{HV}}$ is reduced to $65 \mathrm{~V}, \mathrm{I}_{\mathrm{LV}}$ becomes negative, and $\mathrm{V}_{\mathrm{LV}}$ feeds power to $\mathrm{HV}$ side as the power flow direction has changed. This is shown in Fig. 7(b). To maintain the same current to the LV side, module 5 is bypassed, and the gate signal duty ratio is changed. Thus $I_{L V}$ becomes positive again, and this is shown in Fig. 7(c).

\section{B. Performance analysis of the $5 \mathrm{~kW} M M C C C$}

To test the efficiency and performance of the $5 \mathrm{~kW}$ converter, it was loaded at different voltages and CR. To take these measurements, the MMCCC circuit was operated in down conversion mode. Fig. 8(a) shows the LV side voltage after connecting a resistive load of $1.76 \Omega$ at the LV side and a $250 \mathrm{~V}$ source at the $\mathrm{HV}$ side. For this configuration, the output power was $1984.8 \mathrm{~W}$, the output voltage was $59.2 \mathrm{~V}$, and the circuit was running at $\mathrm{CR}=4$.

As a next step, the circuit's CR was increased to 5 by bypassing 2 modules because 4 active modules generate a CR of 5. During this time, the HV side voltage was $275 \mathrm{~V}$, and the LV side voltage was $52.4 \mathrm{~V}$. At this operating point, the output load consumed $1556.5 \mathrm{~W}$, and the corresponding output voltage is shown in Fig. 8(b).

In the last step, the circuit's CR was increased to 6, and the average dc voltage found was $44.07 \mathrm{~V}$. During this time, the power consumption of the load connected at the LV side was $1100.8 \mathrm{~W}$.

The second part of the experiment was to measure the efficiency of the converter at different input voltages while keeping a fixed load. As the first step, the CR was set to 4 , a fixed load of $1.76 \Omega$ was connected to the $\mathrm{LV}$ side, and the input (HV side) voltage was varied from 0 to $250 \mathrm{~V}$. The input and output power of the converter was measured using a Yokogawa PZ4000 power analyzer, and the efficiency was hand calculated. Thus for varying input voltage, the corresponding efficiency of a 4-level converter is shown in Fig. 9(a). Fig. 9(b) shows the efficiency of the MMCCC in 5-level configuration, and Fig. 9(c) shows it for 6-level. After observing these three figures, two conclusions can be made: 1) the converter has almost flat efficiency characteristics which means that the efficiency is very high even at zero or partial loads, 2) the best possible efficiency is achieved when the CR is high. Thus, when the converter operates in 6-level configuration, the efficiency is higher than 4 or 5-level configuration for the same output power.

The third part of the performance analysis was to measure the efficiency of the converter with varying load and for a fixed input voltage. In this step, the converter was operated at 5-level configuration, and the input voltage was set at $250 \mathrm{~V}$. Then using load banks, the LV side load was varied and the efficiency was measured for variable load condition. The efficiency at different loading conditions is shown in Fig. 10. The load connected at the LV side was varied in the range of 827.4 W to $1384.8 \mathrm{~W}$. In this test, it was found that when the input voltage is fixed, efficiency drops slightly 


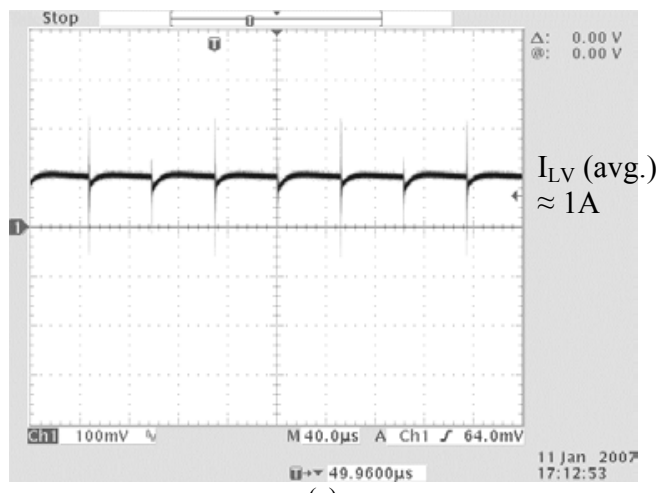

(a)

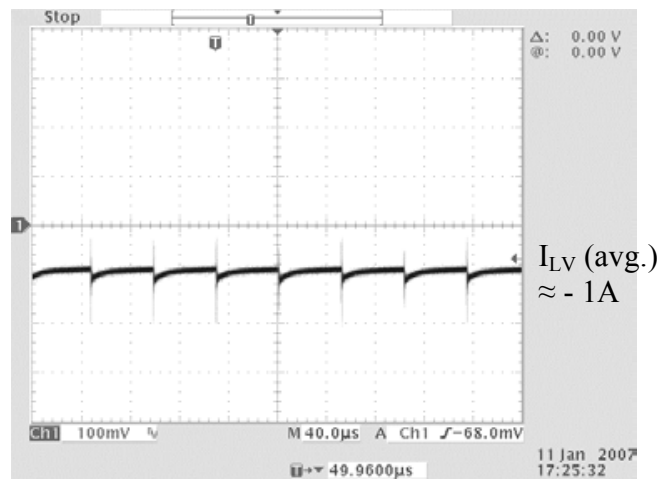

(b)

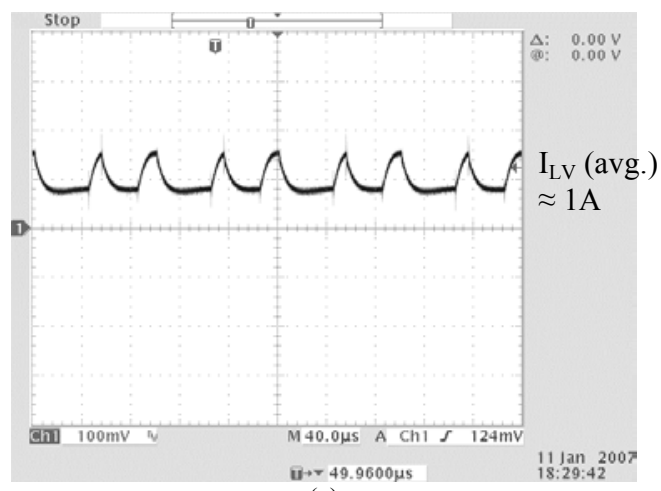

(c)

Fig. 7. Experimental results of the bi-directional power management operation; (a) $\mathrm{I}_{\mathrm{LV}}(10 \mathrm{~A} / \mathrm{V})$ when $\mathrm{V}_{1}$ is feeding power to LV side, (b) $\mathrm{I}_{\mathrm{LV}}(10 \mathrm{~A} / \mathrm{V})$ when $\mathrm{V}_{2}$ is feeding power to $\mathrm{HV}$ side,

(c) $I_{L V}(10 A / V)$ when module 1 is bypassed and the duty ratio of the gate driving signal is controlled to achieve $5<\mathrm{CR}<6$.

with increasing output power or the load current. On the other hand, for a fixed load and varying input voltage, the efficiency increases with output power that can be seen in Fig. 9(b) for a 5-level configuration.

It can be easily sown how Fig. 9(b) and Fig. 10 are consistent. In Fig. 10, when the input of the 5-level converter is fixed at $250 \mathrm{~V}$ and the load is varied, at around $1300 \mathrm{~W}$ output the efficiency of the converter is around $95 \%$. On the other had when the converter has a fixed load of $1.76 \Omega$ and the input voltage is varied, at

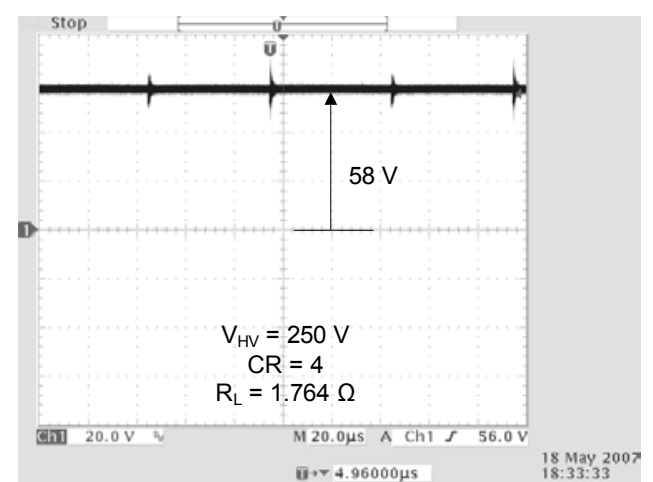

(a)

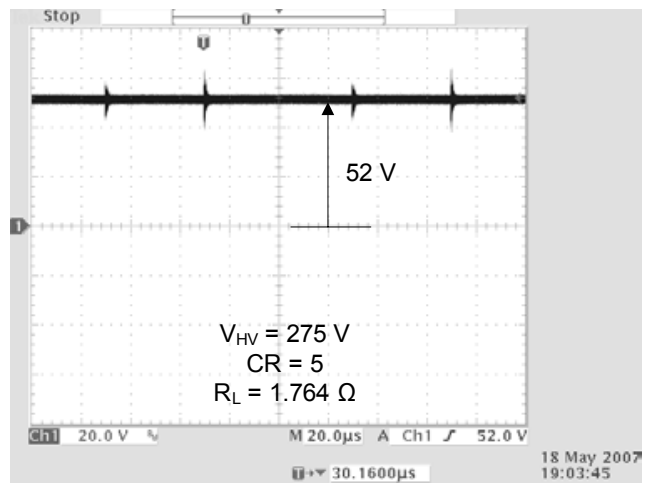

(b)

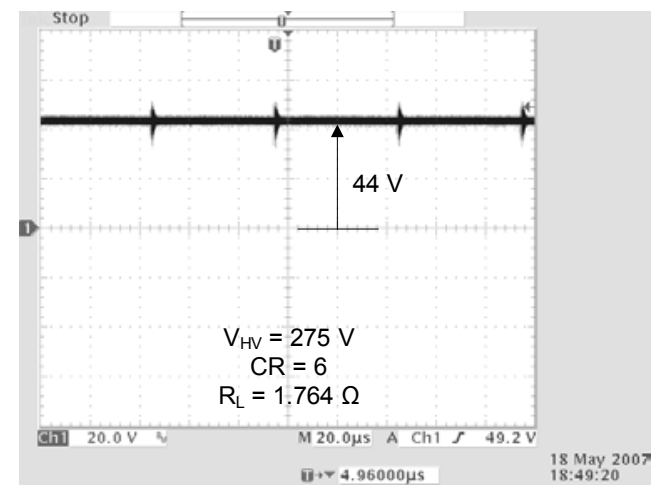

(c)

Fig. 8. Experimental results of the output voltage of the $5 \mathrm{~kW}$ MMCCC in down conversion mode. (a) output voltage $\mathrm{V}_{\mathrm{LV}}$ for $\mathrm{CR}$ of 4, (b) output voltage $V_{\mathrm{LV}}$ at $\mathrm{CR}$ of 5 , (c) $\mathrm{V}_{\mathrm{LV}}$ at $\mathrm{CR}=6$.

$250 \mathrm{~V}$ input, the converter produces $1289 \mathrm{~W}$ output and the corresponding efficiency is $95.1 \%$. This can be found in Fig. 9(b). In this way, the performance of the MMCCC under variable load and variable voltage can be correlated using the test results.

\section{IMPROVED COMPONENT UTILIZATION IN MMCCC}

One of the major advantages of the MMCCC circuit is the improved component utilization over the existing topologies of capacitor clamped dc-dc 


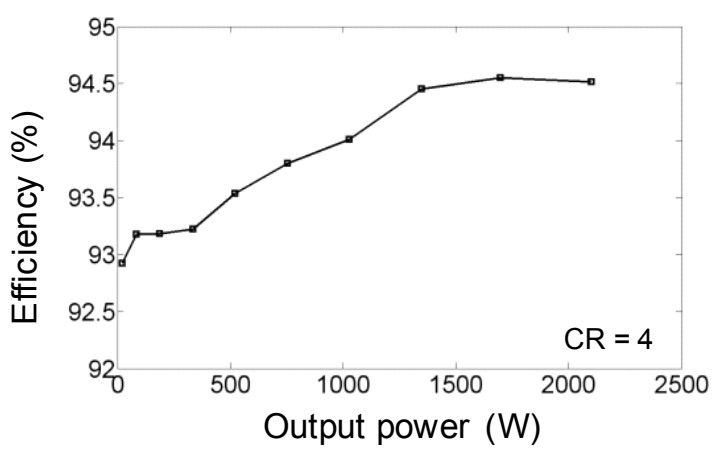

(a)

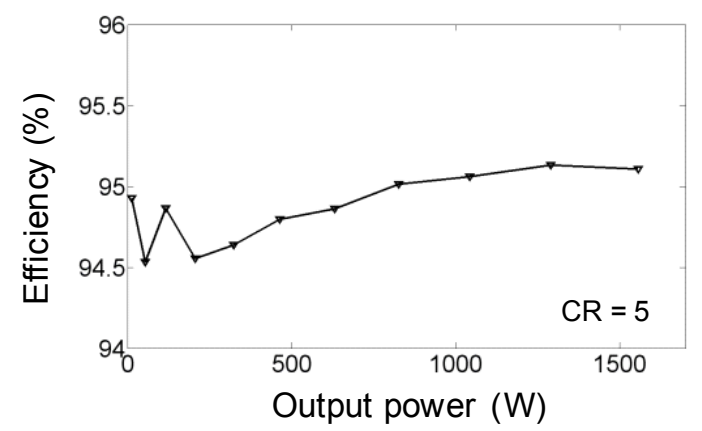

(b)

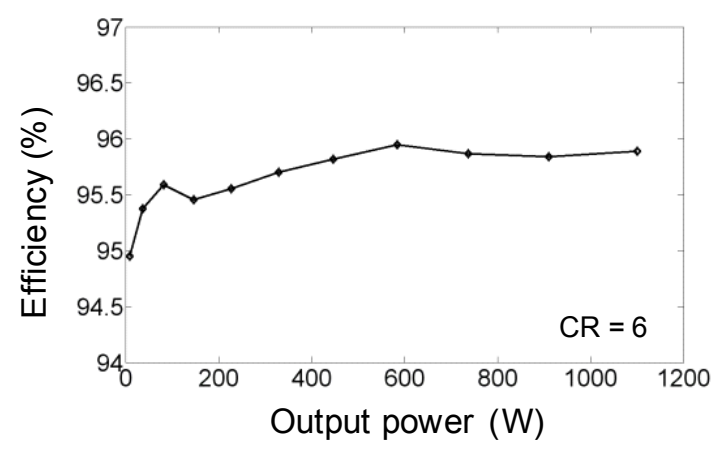

(c)

Fig. 9. The efficiency of the $5 \mathrm{~kW}$ MMCCC converter at different conversion ratio and output power. (a) the efficiency of a 4-level converter with constant load and variable input voltage, (b) the efficiency of a 5-level converter with constant load and variable input voltage, (c) the efficiency of a 6-level converter with constant load and variable input voltage.

converters. This ongoing discussion will compare the component utilization of the MMCCC with the flying capacitor multilevel dc-dc converter (FCMDC) discussed in [10-13]. For a 5-level MMCCC and FCMDC, the power rating is assumed to be $1000 \mathrm{~W}$; and the high side and low side voltages are considered to be $100 \mathrm{~V}$ and $20 \mathrm{~V}$ respectively. For this case, the converter is assumed to operate in down conversion mode. The load connected at the low voltage side will have 50 A current through it.

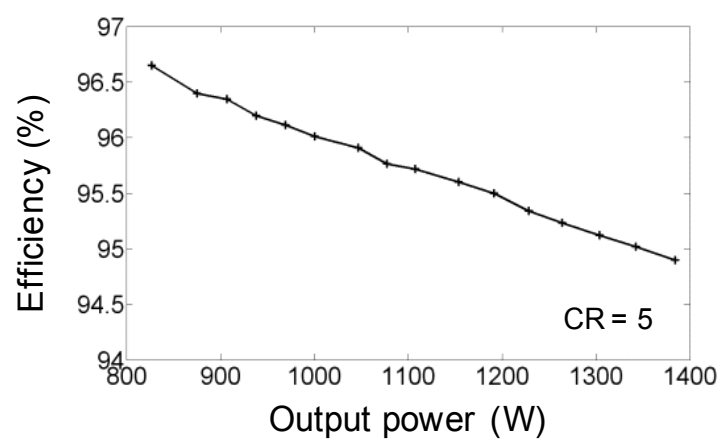

Fig. 10. Efficiency of a 5-level converter with constant input voltage and variable loading condition at the low voltage side.

\section{A. $M M C C C$}

For a 5-level MMCCC, 13 transistors are required to establish a conversion ratio of 5 [13]. Of these 13 transistors, 3 transistors (the top transistor in modules 1 , 2, and 3; as an example, $\mathrm{SB}_{1}$ in Fig. 3) will experience a voltage stress of $2 \mathrm{~V}_{\mathrm{HV}} / \mathrm{N}$, during off time where $\mathrm{N}$ is the conversion ratio, and $\mathrm{V}_{\mathrm{HV}}$ is the high voltage side voltage. Thus, the voltage stress of these three transistors would be $40 \mathrm{~V}$ for this example, and for the other transistors, the voltage stress is $\mathrm{V}_{\mathrm{HV}} / \mathrm{N}=20 \mathrm{~V}$.

The operational diagram of a 5-level MMCCC was explained in [13], and it was shown that the current flows from the high voltage side to the low voltage side in 3 parallel circuits during the first sub-interval. These parallel paths include only the $\mathrm{SR}_{\mathrm{X}}$ transistors. During the second sub interval, the current flows through 2 parallel paths and thereby the current flows through the $\mathrm{SB}_{\mathrm{X}}$ transistors only. Thus, the peak volt-ampere (VA) stress of the 13 transistors used in the circuit is,

$$
\begin{aligned}
& \left(40 \mathrm{~V} \cdot \frac{50 \mathrm{~A}}{3} \cdot 1\right)+\left(40 \mathrm{~V} \cdot \frac{50 \mathrm{~A}}{2} \cdot 2\right)+\left(20 \mathrm{~V} \cdot \frac{50 \mathrm{~A}}{3} \cdot 6\right) \\
& +\left(20 \mathrm{~V} \cdot \frac{50 \mathrm{~A}}{2} \cdot 4\right)=6400 \mathrm{VA}
\end{aligned}
$$

As each transistor operates for $50 \%$ of the total time period, the total average VA rating of the installed transistors would be $3200 \mathrm{VA}$.

\section{B. FCMDC}

The 5-level FCMDC circuit shown in [13] has 10 transistors, and each of them experiences a voltage stress of $20 \mathrm{~V}$. The circuit has 5-sub intervals, and during each sub interval, the load current flows through several transistors connected in series. Thus, there is no parallel operation like the MMCCC that could take place in the FCMDC circuit. The total peak VA rating of the 10 transistors used in the circuit would be,

$$
(20 \mathrm{~V} \cdot 50 \mathrm{~A} \cdot 10)=10,000 \mathrm{VA}
$$


Of these 10 transistors, 5 transistors work for $80 \%$ of the total time period, and 5 transistors work for $20 \%$ of the total time period. Thus, on average, each transistor is operated for $50 \%$ of the total time. So, the total average VA rating of the installed transistors would be $5000 \mathrm{VA}$.

The comparison presented here shows that although the MMCCC circuit uses 3 more transistors; the installed power switching capacity (peak VA stress) of the circuit $(6400 V A)$ is $36 \%$ less than that is required for the FCMDC circuit $(10,000 V A)$. Thus it is possible to build the MMCCC circuit having the same power rating from smaller size components. This advantage of the MMCCC is achieved by virtue of the higher component utilization of the circuit topology.

\section{CONCLUSIONS}

A 5-level 5-kW MMCCC converter has been demonstrated, and the bi-directional power management capability has been explained. Through the experimental results, it was shown that the MMCCC topology has very good efficiency at partial or no-load condition. This $5 \mathrm{~kW}$ converter was tested up to $2 \mathrm{~kW}$, and it is expected to achieve $>94 \%$ efficiency at full load. In addition, the analytical computation proves that this converter has better component utilization compared to the FCMDC circuit. From the analytical calculation it was shown that the total VA stress of the transistors used in the MMCCC circuit is 36\% less than that of the FCMDC circuit. As a result, the MMCCC can be designed to achieve a better power throughput compared to the FCMDC converter. Moreover, using the bi-directional power management feature, the MMCCC topology can be considered as a potential candidate for the power management system for future hybrid or fuel cell automobiles.

\section{REFERENCES}

[1] John. G. Kassakian, David J. Perreault, "The Future of Electronics in Automobiles," Proceedings of $13^{\text {th }}$ International Symposium on Power Semiconductor Devices \& ICs, pp. 15-19, June 2001.

[2] John. G. Kassakian, "Automotive Electrical Systems - The Power Electronics Market of the Future," IEEE/APEC, vol. 1, pp. 3-9, Feb. 2000.

[3] A. Emadi, S. Williamson, and A. Khaligh, "Power Electronics Intensive Solutions for Advanced Electric, Hybrid Electric, and Fuel Cell Vehicular Power Systems," IEEE Trans. of Power Electronics, vol. 21, no. 3, pp. 567-577, May 2006.

[4] K. D. T. Ngo, R. Webster, "Steady-State Analysis and Design of a Switched-Capacitor DC-DC Converter," IEEE Transactions on Aero. and Elec. Systems, vol. 30, no. 1, pp. 92-101, Jan. 1994.

[5] W. Harris, K. Ngo, "Power Switched-Capacitor DC-DC Converter, Analysis and Design," IEEE Transactions on Aero. and Elec. Systems, vol. 33, no. 2, pp. 386-395, April 1997.

[6] S. V. Cheong, H. Chung, A. Ioinovici, "Inductorless DC-to-DC Converter with High Power Density," IEEE Transactions on Industrial Electronics, vol. 41, no. 2, pp. 208-215, April 1994.

[7] O. Mak, Y. Wong, A. Ioinovici, "Step-up DC Power Supply Based on a Switched-Capacitor Circuit," IEEE Transactions on Industrial Electronics, vol. 42, no. 1, pp. 90-97, Feb. 1994.

[8] C. K. Tse, S.C. Wong, M. H. L. Chow, "On Lossless SwitchedCapacitor Power Converters," IEEE Transactions on Power Electronics, vol. 10, no. 3, pp. 286-291, May 1995.

[9] E. Bayer, "Optimized Control of the 'Flying'-Capacitor Operating Voltage in 'Gear-Box' -Charge Pumps, - The Key Factor for a Smooth Operation," IEEE Power Electronics Specialists Conference, pp. 610-615, June 2003.

[10] Z. Pan, F. Zhang, F. Z. Peng, "Power Losses and Efficiency Analysis of Multilevel DC-DC Converters," IEEE Applied Power Electronics Conference, pp. 1393-1398, March 2005.

[11] F. Zhang, F. Z. Peng, Z. Qian, "Study of Multilevel Converters in DC-DC Application," IEEE Power Electronics Specialists Conference, pp. 1702-1706, June 2004.

[12] F. Z. Peng, F. Zhang, Z. Qian, "A Novel Compact DC-DC Converter for 42V Systems," IEEE Power Electronics Specialists Conference, pp. 33-38, June 2003.

[13] F. H. Khan, L. M. Tolbert, "A Multilevel Modular CapacitorClamped DC-DC converter," IEEE Industry Applications Annual Meeting (IAS), Oct. 2006, pp. 966-973. 